\title{
Budd-Chiari syndrome treated by Senning operation
}

\author{
M J MAHONY, " J M LITTLEWOOD, ${ }^{*}$ M S LOSOWSKY, $†$ P J ROBINSON, $\ddagger$ AND G R GILES $\$$ \\ Departments of "Paediatrics, †Medicine, $¥$ Radiology, and $\$$ Surgery, St James’s University Hospital, Leeds
}

SUMMARY Budd-Chiari syndrome was diagnosed in a 13 year old boy who presented with ascites. Angiographic studies showed occlusion at the ostia of the hepatic veins. This was treated surgically by the Senning operation of transcaval dorsocranial resection of the liver and hepatocaval anastomosis. The patient's ascites cleared and he remains well 10 months after surgery.

Budd-Chiari syndrome is characterised by hepatic venous outflow obstruction. The obstruction may occur at any point from the efferent vein of the hepatic lobule to the supradiaphragmatic part of the inferior vena cava. In Parker's review of 115 cases of idiopathic Budd-Chiari syndrome $44 \%$ were associated with occlusion of the hepatic vein ostia, but most cases also had distally situated lesions.' Although in many instances the aetiology is obscure, certain causes are well known. These include thrombotic disorders such as polycythaemia, oral contraception, systemic lupus erythematosus, and paroxysmal nocturnal haemoglobinuria. Tumour invasion of the hepatic veins and inferior vena cava-for example, by Wilms' tumour-is well recognised. Webs in the inferior vena cava, presumably congenital, cause membranous intraluminal obstruction. Veno-occlusive disease of the liver associated with drinking bush teas is a relatively common cause of the syndrome in certain parts of the world. Budd-Chiari syndrome may be a sequel to blunt abdominal trauma such as road traffic accidents. Constrictive pericarditis may present as Budd-Chiari syndrome.2

The potential for corrective surgery is limited to those cases where a discrete distal anatomical lesion such as a congenital web in the inferior vena cava is found. ${ }^{3}$ Senning has devised a technique of transcaval dorsocranial resection of the liver in cases of juxtacaval hepatic vein occlusion. ${ }^{+}$We describe a 13 year old boy who presented with Budd-Chiari syndrome secondary to hepatic vein occlusion who was successfully treated by a Senning procedure.

\section{Case history}

This 13 year old Asian boy was referred with a two month history of ascites. He had been well apart from a road traffic accident six years previously when he was knocked down by a car and struck in the abdomen and legs. He presented as a thin boy, his weight was $34 \mathrm{~kg}$ (10th centile), his height $142 \mathrm{~cm}$ (10th centile). He was not jaundiced and there were no signs of chronic liver disease. Abdominal examination showed gross ascites and $3 \mathrm{~cm}$ hepatomegaly. The differential diagnosis at time of admission was tuberculous peritonitis, malignancy, or chronic liver disease.

Results of initial investigations included haemoglobin $12.3 \mathrm{~g} / \mathrm{l}$, erythrocyte sedimentation rate was $1 \mathrm{~mm}$ in the first hour, prothrombin ratio $1 \cdot 5$. The results of liver function tests were: bilirubin concentration $24 \mu \mathrm{mol} / 1$, alanine aminotransferase activity 27 IU/l, and alkaline phosphatase activity 399 $\mathrm{KAU} / \mathrm{l}$. Albumin concentration was $40 \mathrm{~g} / \mathrm{l}$. Diagnostic paracentesis of the abdomen showed a protein content of $28 \mathrm{~g} / \mathrm{l}$, no organisms or malignant cells and no acid fast bacilli. Mantoux test $1 / 10000$ was negative. A computed tomogram of the abdomen showed ascites but no evidence of an intraabdominal mass. He then had an exploratory laparotomy at which $600 \mathrm{ml}$ of ascitic fluid was removed. The liver was swollen, hard, and micronodular. Histology of an open liver biopsy specimen taken at laparotomy showed centrilobular distention and congestion consistent with early Budd-Chiari syndrome.

Abdominal ultrasound examination showed ascites, normal liver texture, and patent hepatic veins. An echocardiogram showed normal cardiac structure and function with no evidence of pericardial constriction. An inferior venacavogram via the left femoral vein was performed during which the catheter passed freely from the inferior vena cava into the right atrium thus excluding a web in the inferior vena cava. Contrast injection showed side to side narrowing of the intrahepatic part of inferior vena cava. Transcatheter pressure measurements made above and below the narrowing showed a pressure gradient of $10 \mathrm{~cm}$ of water. The hepatic veins could not be entered and on contrast injection there was no retrograde filling of the hepatic veins. Only a small cluster of veins in the caudate lobe could be opacified (fig 1). The appearances were interpreted as showing hepatic vein occlusion and extrinsic compression of the inferior vena cava. This was confirmed by percutaneous transhepatic 


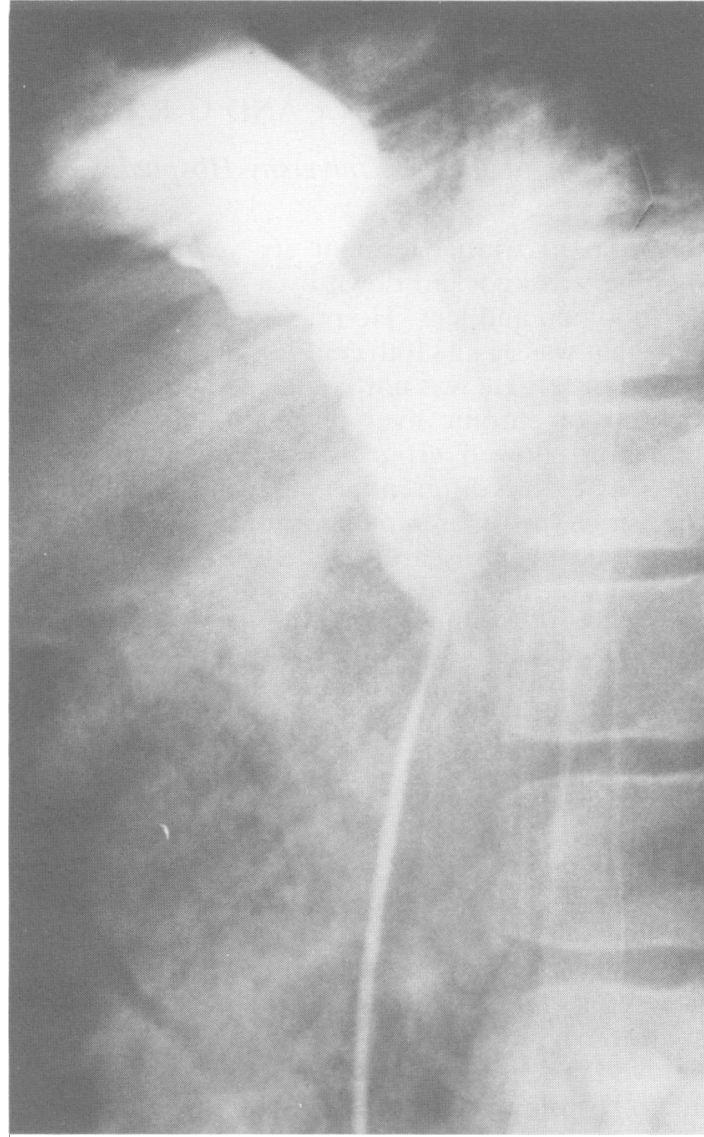

Fig 1 Lateral view of inferior vena cavogram showing local concentric narrowing of intrahepatic part of the inferior vena cava.

venography. Contrast injected into the liver parenchyma from the right axilla using a 22 gauge needle outlined normal branching hepatic veins in the right and left lobes. Flow was sluggish and the hepatic veins were occluded at their ostia (fig 2 ).

Management of the ascites included salt restriction to $20 \mathrm{mmol} /$ day and fluid restriction to $800 \mathrm{ml}$. Diuretics were given as spironolactone $100 \mathrm{mg}$ three times a day and frusemide $30 \mathrm{mg}$ daily. The prothrombin ratio increased to a maximum of 2.5 and was treated by injections of vitamin K. Serum albumin fell to $27 \mathrm{~g} / \mathrm{l}$ and was maintained by intermittent infusions of salt poor albumin.

He then underwent a Senning operation. The heart was exposed via a median sternotomy incision and he was placed on cardiopulmonary bypass. The abdomen was opened to the umbilicus. Several litres

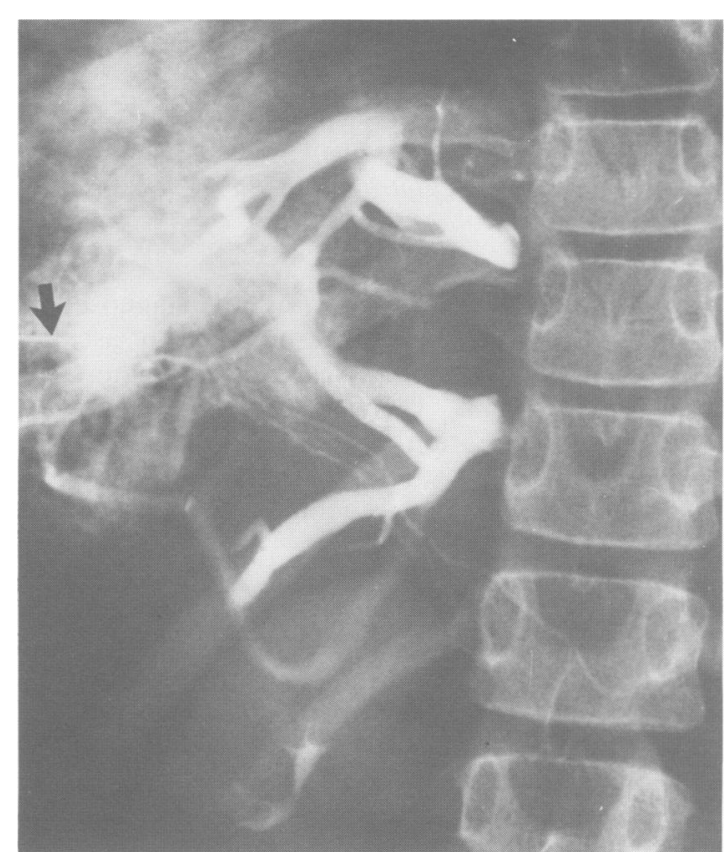

Fig 2 Percutaneous transhepatic venography.

Parenchymal contrast injection into right lobe (arrow) showing patency of intrahepatic veins and occlusion at ostia of the hepatic veins.

of ascitic fluid were aspirated and both lobes of the liver were seen to be grossly congested. The diaphragm was split vertically and the inferior vena cava was dissected until it disappeared into the liver. The inferior vena cava was opened longitudinally starting in the supradiaphragmatic portion and carried down into the liver. Dissection of a vertical incision into the liver substance and excision of liver tissue anterior to the caval wall allowed the identification of hepatic radicles in the right and left lobes. These were difficult to identify owing to considerable fibrosis and thickening of the surrounding liver tissues. These venous radicles were opened up with probes and immediate drainage of large quantities of blood resulted with considerable decompression of the liver. A hepatocaval anastomosis was then performed opposing the liver to the cardiac end of the inferior vena cava. The inferior vena cava was closed transversely by continuous suture so as to widen the cava immediately above the liver.

Postoperative recovery was uneventful. Liver function tests, albumin concentrations, and prothrombin ratio returned to normal values. The patient remains well, and is free of ascites and off all medication at follow up 10 months after surgery. 


\section{Discussion}

Diagnosis of chronic Budd-Chiari syndrome should be considered in patients presenting with ascites, hepatomegaly, and normal or mildly deranged liver function tests. The diagnosis may be suspected if a technetium colloid liver scan shows decreased hepatic isotope uptake, except in the caudate lobe where uptake may be normal or increased; or if hepatic veins with normal blood flow, as shown by Doppler imaging, cannot be identified on ultrasound scanning. Definitive diagnosis is made by a liver biopsy specimen showing the characteristic appearance of centrilobular sinusoidal distension.

Patients with chronic Budd-Chiari syndrome are a heterogenous group because of its multifactorial aetiology, and prognosis for individual cases is variable. The overall prognosis is poor with a five year survival of $20-50 \%$. A recently reported series associated poor prognosis with malignancy, paroxsymal nocturnal haemoglobinuria, hepatic failure, and portal hypertension." A better prognosis was associated with remediable causes such as surgically treatable webs in the inferior vena cava.

The angiograpic techniques of cavography and percutaneous transhepatic venography allow the vascular pathology of chronic Budd-Chiari syndrome to be localised precisely. ${ }^{\circ}$ Other reports have emphasised the potential for surgical management of inferior vena cava webs. ${ }^{3}$ Previously the prog- nosis for patients with hepatic vein occlusion was poor but the Senning procedure offers treatment for this group.

The aetiology of this boy's hepatic vein occlusion is uncertain. The collagenous reaction which occluded the hepatic veins may have been secondary to trauma sustained in a road traffic accident. The present case shows the value of full angiographic study of patients with chronic Budd-Chiari syndrome as localisation of the site of obstruction may allow remedial surgery.

\section{References}

' Parker RGF. Occlusion of the hepatic veins in man. Medicine' 1959:38:369-402.

2 Sherlock S. Diseases of the liver and biliary system. 7th ed. Oxford: Blackwell, 1985.

3 Yamamoto S. Yokoyama Y. Takeshige K. I watsuki S. BuddChiari syndrome with obstruction of the inferior vena cava. Gastroenterology 1968:54:1(07()-84.

+ Senning A. Transcaval posterocranial resection of the liver as treatment of the Budd-Chiari syndrome. World J Surg 1983:7:632-40)

5 Gupta S. Blumgart LH. Hodgson HJF. Budd-Chiari syndrome: long-term survival and factors affecting mortality. Q J Med 1986:232:781-91.

"Clain D. Freston J. Kreel J. Sherlock S. Clinical diagnosis of the Budd-Chiari syndrome. Am J Med 1967:43:544-54.

Correspondence to Dr MJ Mahony, Department of Paediatrics. St James's University Hospital. Beckett Street. Leeds LS9 7TF.

Accepted 18 January 1988 